\title{
EXPRESSION OF p53 IN OLIGODENDROGLIOMAS
}

\author{
JOHAN M. KROS* ${ }^{*}$, JOSIANE J. C. J. GODSCHALK*, KAUSILIA K. KRISHNADATH* AND CORBERT G. VAN EDEN $\dagger$ \\ *Department of Pathology, University Hospital Rotterdam-Dijkzigt, Erasmus University Rotterdam, \\ Dr Molewaterplein 40, 3015 GD Rotterdam, The Netherlands; †The Netherlands Institute for Brain Research, \\ Meibergdreef 33, $1105 \mathrm{AZ}$ Amsterdam, The Netherlands
}

Received 21 June 1993

Accepted 3 August 1993

\begin{abstract}
SUMMARY
The expression of the nuclear protein p53 in oligodendrogliomas was investigated by immunohistochemistry, using a monoclonal anti-p53 antibody (DO-7) on formalin-fixed, paraffin-embedded material in 84 histologically verified cases, and compared with the histopathological grade and survival. p53-immunoreactive cells were found in 75 per cent of the samples acquired at the first biopsy. The p53 labelling index was not related to the degree of nuclear anaplasia. Tumour cases with more than 75 per cent p53 immunostained cells had a rapidly fatal clinical course. However, no significant correlation was found between p 53 labelling index and tumour grade, mitotic index, or ploidy status. In most tumour recurrences $(n=25)$, the p53 labelling index increased or remained at the level of the first biopsy. In five cases ( 6 per cent), p53 was absent in the first sample as well as in the recurrence. Irrespective of the underlying aberration of either the gene or the metabolic pathway of $p 53$, it is concluded that a high percentage (i.e., more than 75 per cent) of p53-immunolabelled cells is predictive of an unfavourable clinical course, while a percentage lower than 75 per cent immunoreactive cells does not exclude a rapid fatal outcome.
\end{abstract}

KEY WORDS--Oligodendroglioma, immunohistochemistry, p53, tumour suppressor gene, mitotic index, DNA flow cytometry.

\section{INTRODUCTION}

When DNA of normal cells is damaged, the nuclear protein $\mathrm{p} 53$ is thought to accumulate and arrest the cell cycle at G1, presumably in order to enable repair of DNA damage. ${ }^{1}$ If $\mathrm{p} 53$ is disrupted, genetically unstable clones could continue to divide, resulting in the accumulation of mutations and chromosomal rearrangements in subsequent generations. ${ }^{2}$ While in non-neoplastic cells p53 expression is almost always below the level of immunohistochemical detection, ${ }^{3}$ mutations in

tCurrently research fellow in the Neuropathology Laboratory of the Department of Pathology, University of Washington, Seattle.

Addressee for correspondence: Johan M. Kros, MD, Ph.D., University of Washington, Department of Pathology, Neuropathology Laboratory RJ-05, Seattle, WA 98195-0001, U.S.A.

Reprint requests: Johan M. Kros, MD, Ph.D., Department of Pathology, Neuropathology Laboratory, University Hospital Rotterdam-Dijkzigt, Dr Molewaterplein 40, 3015 GD Rotterdam, The Netherlands. the p53 gene or aberrations in p53 degradation may result in elevated levels of the p 53 protein, permitting its immunohistochemical detection. Although the connection between disruption of the p53 system and development of tumours remains speculative, p53 is immunohistochemically detectable in a wide variety of tumours. ${ }^{40}$ In many, $4,5,8,9,12-14,16,18-20$ though not all $6,7,10,15,17$ human cancers, p53 immunoreactivity was found to be associated with morphological and cell proliferation-related tumour characteristics.

In astrocytomas, the number of p53 immunoreactive cells reportedly correlated well with malignancy grades. ${ }^{21-24}$ Despite the demonstration of p53 mutations in oligodendrogliomas, ${ }^{25}$ p53 immunoreactive cells have been recorded in only a few cases that have been investigated so far, ${ }^{21,22,24}$ while no data relating p53 immunohistochemistry to tumour grade or clinical course are available.

The aim of this retrospective study was to investigate immunoreactivity for $\mathrm{p} 53$ in 84 cases and to 
link the percentages of p53-positive cells with the histopathological grades and clinical courses. In addition, the data were correlated with the results of counting mitoses and DNA flow cytometry obtained in a previous study on the same group. ${ }^{26}$

\section{MATERIALS AND METHODS}

\section{Clinical records}

The clinical data and formalin-fixed, paraffinembedded material of 111 patients with cerebral oligodendrogliomas were taken from the files of the University Hospital Rotterdam-Dijkzigt. In addition, tissues of ten patients with conditions leading to reactive gliosis were processed. The same samples of oligodendrogliomas have been used earlier in a retrospective study on the implications of DNA flow cytograms on the biological behaviour of oligodendrogliomas. ${ }^{26}$ Adequate follow-up was obtained in 84 cases. The patients had been admitted to the hospital between 1972 and 1986. The age distribution at the first operation showed peaks around 35 and 55 years. Craniotomy was performed in order to decompress the brain or debulk the tumour. Patients who died within 2 weeks postoperatively were excluded from the study, since this short postoperative survival was considered as death related to surgical complications. Survival times were calculated from the date of the first craniotomy. All patients had died by the end of the study.

\section{Grading the oligodendrogliomas and assessing the mitotic count}

p53-immunohistochemistry was performed on slides adjacent to those used for histopathological grading, DNA flow cytometry, and counting mitoses in an earlier study. ${ }^{26}$ The tumours were graded according to the scheme of Smith et al., ${ }^{27}$ taking endothelial proliferation, necrosis, nucleus to cytoplasm ratio, cell density, and pleomorphism into account. The variables were scored in a simple present-absent scheme, resulting in the attribution of four grades. The scheme has been proven to correlate significantly with survival. ${ }^{27,28}$ The mitotic count was assessed by first selecting the highest cell density areas followed by randomly choosing fields, and then calculating the quotient of the number of mitoses and the total number of cells in the fields (objective $\times 400$ ). The scores were grouped into three categories: a category of less than one mitosis; a category of more than five mitoses; and an intermediate group.

\section{Immunohistochemistry}

Immunohistochemistry was performed on $5 \mu \mathrm{m}$ sections. The slides were deparaffinized and endogenous peroxidase activity was blocked with 3 per cent hydrogen peroxide $\left(\mathrm{H}_{2} \mathrm{O}_{2}\right)$ in methanol, followed by preincubation with 5 per cent normal goat serum diluted in phosphate-buffered saline and bovine serum albumin (PBS-BSA) for $15 \mathrm{~min}$ at $37^{\circ} \mathrm{C}$. All incubations were performed in a humidified chamber. The primary antibody was mouse anti-p53 (DO-7), diluted 1:25 in PBS overnight at $4^{\circ} \mathrm{C}$. DO-7 (Dako, Denmark) was raised against recombinant human wild-type p53 protein expressed in Escherichia coli. This antibody recognizes an epitope in the $\mathrm{N}$-terminus of the human p53 protein, residing between amino acids 35 and 45 . Rinsing the excess antibodies or conjugates was done by three 5 min washes in PBS. The avidin-biotin-peroxidase complex method was used as the detection system. Incubation with the biotinylated goat anti-mouse immunoglobulin (Dako, Denmark) diluted 1:400 was followed by incubation with avidin and biotinylated peroxidase complexes (Dako, Denmark) for $30 \mathrm{~min}$ at room temperature. Final visualization was achieved by incubation with 0.02 per cent diaminobenzidine (DAB) in PBS and 0.075 per cent $\mathrm{H}_{2} \mathrm{O}_{2}$ for $7 \mathrm{~min}$ in darkness. As a control, the primary antibody was replaced by PBS. The slides were counterstained with haematoxylin.

\section{Scoring p53-positive cells}

The percentage of p53-positive cells was established by the quotient of the number of p53positive cells and the total number of cells per ten fields $\times 400$ magnification using a grid. The counts were repeated. The p53 labelling index (LI) was defined as $100 \times$ number of labelled nuclei $\div$ total number of nuclei counted. Five groups were distinguished: a group without positive cells and four groups with increasing LI (i.e., 1-25 per cent; 26-50 per cent; $51-75$ per cent; more than 75 per cent).

\section{Statistics}

The statistical tests were performed using the Statistical Package for the Social Sciences (SPSSX package). Since the frequency distribution of the survival times of the patients was exponential, e-log transformation was performed in order to allow the use of parametric tests. Analysis of variance (ANOVA) was used for the detection of 

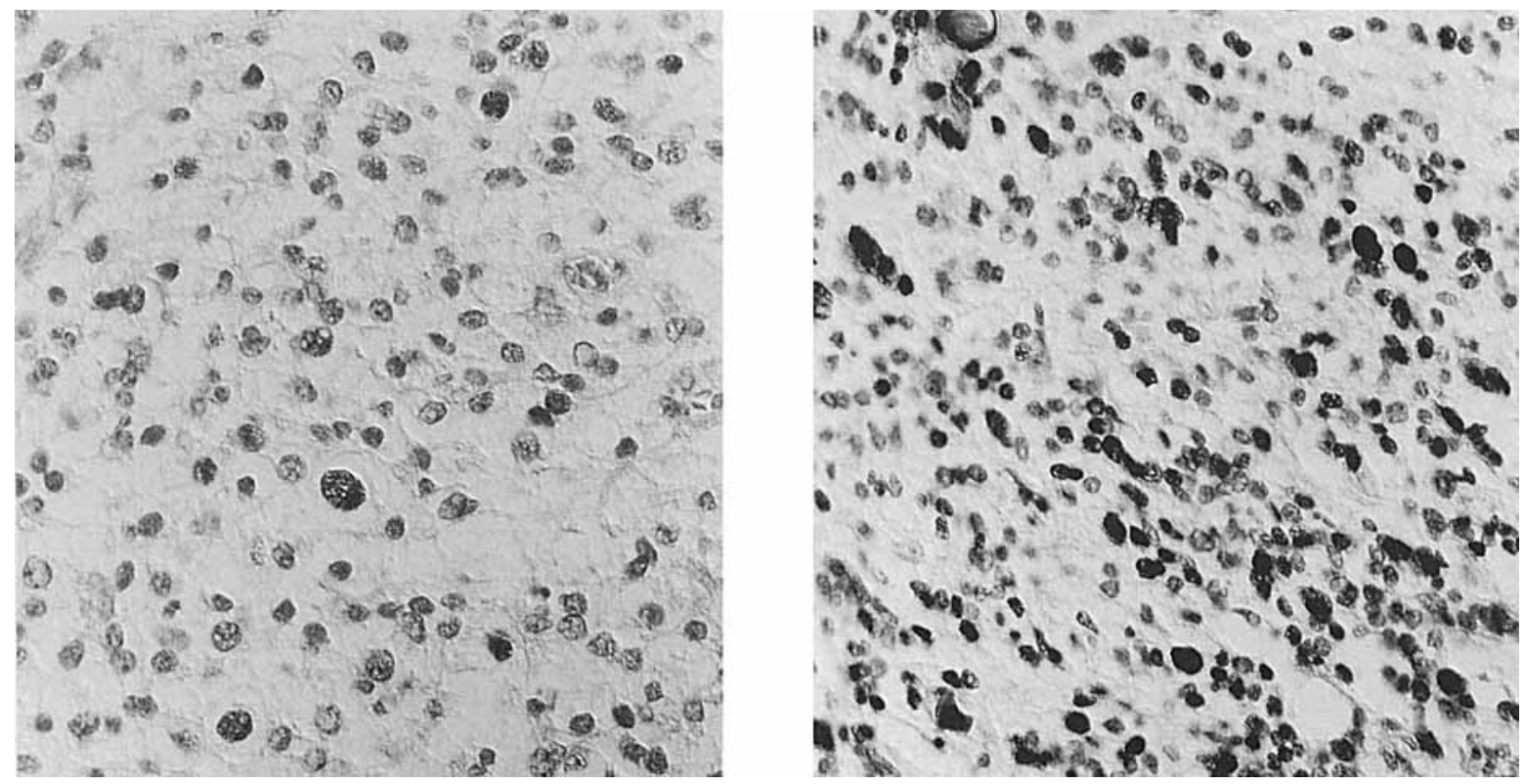

Fig. 1- (a) Oligodendroglioma grade B, stained for p53. Clonal patterns of $\mathrm{p} 53$-positive cells were not distinguished; $\mathrm{p} 53$-positive cells were always intermingled with p53-negative cells. (b) Oligodendroglioma grade C, stained for p53. p53 immunoreactivity was independent of the degree of nuclear anaplasia

the main effects of the grading scheme and the p53 LI. A posteriori testing was done using the Student-Newman-Keuls test with significance at the 0.05 level. Dependences between the results of p53 immunostaining and those of histopathological grading, DNA flow cytometry, and counting mitoses were tested by calculating Cramér's contingency coefficient.

\section{RESULTS}

Control sections of normal brain (grey and white matter) and sections of reactive gliosis did not contain p53-positive cells. The positive nuclei showed a granular staining pattern. Staining was always confined to the nucleus and was not seen in the cytoplasm of the neoplastic cells (Figs 1a and lb). Endothelial cells were always negative for p53, even when endothelial proliferation was present.

Seventy-five per cent of the oligodendrogliomas contained p53-positive cells, while 25 per cent of the tumours did not have any positive cells (Table I). The inter-observer variability was about 5 per cent; the intra-observer variability remained below 2 per cent. The mean survival times for the five
Table I-Survival times for p53 labelling index (LI)

\begin{tabular}{crrrrr}
\hline & & \multicolumn{3}{c}{ Survival time (months) } \\
\cline { 3 - 6 } p53 LI & $n$ & Mean & SD & SEM \\
\hline $0 \%$ & 21 & $(25 \%)$ & 34.95 & $30 \cdot 48$ & $6 \cdot 66$ \\
$1-25 \%$ & 23 & $(27 \%)$ & $52 \cdot 83$ & $59 \cdot 81$ & $12 \cdot 46$ \\
$26-50 \%$ & 23 & $(27 \%)$ & $29 \cdot 61$ & 30.69 & $6 \cdot 39$ \\
$51-75 \%$ & 10 & $(12 \%)$ & 35.60 & $28 \cdot 81$ & $9 \cdot 12$ \\
$>75 \%$ & 7 & $(8 \%)$ & $9 \cdot 29$ & $2 \cdot 93$ & $1 \cdot 11$ \\
& & & & & \\
\cline { 2 - 3 } & $84(100 \%)$ & & & \\
\hline
\end{tabular}

$n=$ number of patients; mean=mean survival time; $\mathrm{SD}=$ standard deviation; $\mathrm{SEM}=$ standard error of the mean.

groups based on p53 LI are listed in Table I, and the corresponding survival curves are plotted in Fig. 2. The curve of the highest p53 LI (i.e., $>75$ per cent) falls the fastest, and a significant difference between this curve and the curves of tumours with a p53 LI of less than 75 per cent was found $(P<0.05)$ (Fig. 2). The mean survival times for the four groups distinguished by the grading system are listed in Table II. An increase in tumour grade 


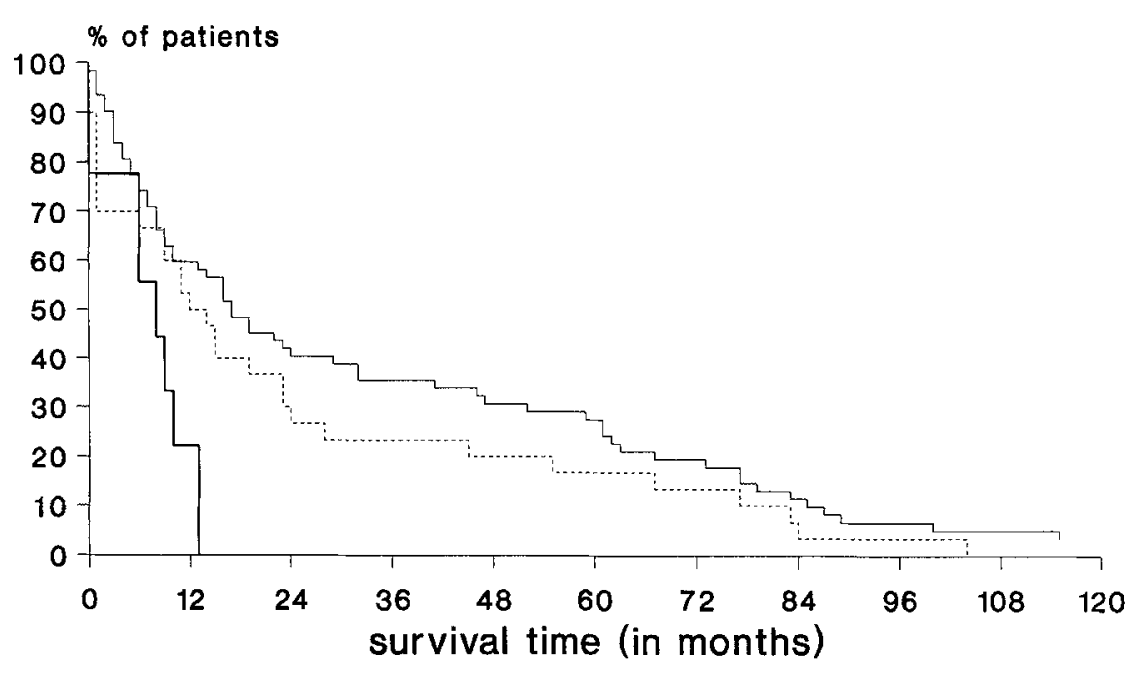

p53 Ll=0\%

p53 Ll=1-75\%

p53 LI > 75\%

Fig. 2-Survival curves according to the percentages of p53-positive cells. The curve for $\mathrm{p} 53$ LI between 75 and 100 per cent is clearly separated from the curves for all distinct LI groups lower than 75 per cent. Only one high-grade tumour (grade D) was found among the seven samples in the $>75$ per cent curve (Table III)

Table II-Survival times for histopathological grades

\begin{tabular}{|c|c|c|c|c|c|}
\hline \multirow{2}{*}{$\begin{array}{l}\text { Histopathological } \\
\text { grades }\end{array}$} & \multirow{2}{*}{\multicolumn{2}{|c|}{$n$}} & \multicolumn{3}{|c|}{ Survival time (months) } \\
\hline & & & Mean & SD & SEM \\
\hline A & 22 & $(26 \%)$ & 56.36 & $59 \cdot 98$ & $12 \cdot 79$ \\
\hline B & 41 & $(49 \%)$ & 32.77 & $31 \cdot 50$ & 4.92 \\
\hline C & 6 & $(7 \%)$ & $31 \cdot 33$ & $30 \cdot 71$ & $12 \cdot 53$ \\
\hline \multirow[t]{2}{*}{$\mathrm{D}$} & 15 & $(18 \%)$ & $17 \cdot 20$ & $19 \cdot 72$ & $5 \cdot 10$ \\
\hline & & $(100 \%)$ & & & \\
\hline
\end{tabular}

See footnote to Table I.

parallels a decrease in mean survival. The survival rates for the two intermediate grades (i.e., grades B and $\mathrm{C}$ ) are virtually indistinguishable. ANOVA showed a main effect of the grading system on the survival rates $(P=0.035)$. A posteriori testing (Student-Newman-Keuls) revealed a significant difference between grades $\mathrm{A}$ and $\mathrm{D}$ at the 0.05 level.

Table III represents the crosstable between p53 LI and histopathological grade. No correlation between the results of p53 immunostaining and histopathological grading was found (Cramér's contingency coefficient $=0.444 ; P=0.194$ ).
Table III-Cross-table histopathological grades versus p53 LI

\begin{tabular}{cccccc}
\hline & \multicolumn{4}{c}{ Histopathological grade } & \\
\cline { 2 - 4 } p53 LI & $\mathrm{A}$ & $\mathrm{B}$ & $\mathrm{C}$ & $\mathrm{D}$ & Total \\
\hline 0 & $11 \%$ & $14 \%$ & 0 & $4 \%$ & $29 \%$ \\
$1-25 \%$ & $6 \%$ & $9 \%$ & $3 \%$ & $9 \%$ & $27 \%$ \\
$26-50 \%$ & $5 \%$ & $14 \%$ & $1 \%$ & $5 \%$ & $25 \%$ \\
$51-75 \%$ & $2 \%$ & $5 \%$ & $2 \%$ & $2 \%$ & $11 \%$ \\
$>75 \%$ & 0 & $5 \%$ & $1 \%$ & $1 \%$ & $7 \%$ \\
Total & $24 \%$ & $47 \%$ & $7 \%$ & $21 \%$ & $100 \%$ \\
\hline
\end{tabular}

Cramér's contingency coefficient $=0 \cdot 444 ; P=0-194$.

Thirty-one per cent of the oligodendrogliomas were DNA diploid, 39 per cent had a DNAtetraploid pattern, while 31 per cent were aneuploid. ${ }^{26}$ Although the mitotic count correlated with the survival time $(P<0 \cdot 0038)$, the ploidy status did not. ${ }^{26}$ No dependence between the ploidy status of the oligodendrogliomas and the p53 LI (Cramér's contingency coefficient $=0.323 ; P=0.527$ ) was found.

In 26 per cent of the tumours, no mitoses within 3 HPF (high-power fields) were seen. In 57 per cent the mitotic count was between 1 and 5 , while in 17 
Table IV-Cross-table p53 LI in successive biopsies $(n=25)$

\begin{tabular}{|c|c|}
\hline & p53 expression in primary tumour \\
\hline recurrence & $1-25 \% \quad 26-50 \%$ \\
\hline
\end{tabular}

\begin{tabular}{llllll}
\hline 0 & 5 & 0 & 1 & 0 & 0 \\
$1-25 \%$ & 1 & 4 & 2 & 2 & 0 \\
$26-50 \%$ & 0 & 0 & 1 & 0 & 0 \\
$51-75 \%$ & 1 & 2 & 2 & 0 & 0 \\
$>75 \%$ & 0 & 1 & 2 & 1 & 0 \\
\hline
\end{tabular}

In ten cases the p53 LI was equal in both biopsies, wheras in another ten cases the level of demonstrable p 53 had increased. In five cases the p53 LI in the recurrence was lower than that in the initial biopsy, most likely caused by sampling errors. Only in two cases was expression of p53 found in the recurrence, while the primary tumour was immunonegative. In five cases, p53 was demonstrable neither in the primary tumour, nor in the recurrence.

per cent more than five mitoses were counted. ${ }^{26}$ No dependence between the mitotic index and the p53 LI was found (Cramér's contingency coefficient $=0.282 ; P=0.510$ ).

Table IV compares the p53 LI of the first biopsy with that of the second biopsy in the 25 patients who underwent craniotomy for recurrent tumour. In ten cases, no change in the p53 LI was observed in the two successive biopsies. In ten cases, an increase in p53 expression in the recurrent specimen was seen. In five cases, the p53 LI was lower in the second specimen. In two cases, the absence of p53 in the primary biopsy was followed by demonstrable $\mathrm{p} 53$ in the recurrence. In five cases, p53 was found in neither the first nor the second sample (Table IV).

\section{DISCUSSION}

The present finding of $\mathrm{p} 53$-immunolabelled cells in the majority of oligodendrogliomas is compatible with the finding of mutations in the p53 gene in these tumours. ${ }^{25}$ The low percentages of p53 immunoreactive cells encountered in oligodendrogliomas reported previously might be explained by the small numbers of tumours investigated. ${ }^{21,22,24,29}$ There are, however, some pitfalls in the interpretation of the results of p53 immunohistochemistry. ${ }^{30}$ Negative immunostaining in the presence of a mutation might be the result of gross deletion abolishing all p53 production or, alternatively, may imply that the protein product of the mutated gene has remained unstable, and thus undetectable by immunohistochemistry. Positive p53 immunohistochemistry without a mutation present may be due to an interruption of the normal degradative pathway of $\mathrm{p} 53$. In a recent paper on 34 astrocytomas, comparing the results of p53 immunohistochemistry with those of single-strand conformational polymorphism (SSCP), cases of either false-negative or false-positive immunohistochemistry were shown. ${ }^{31}$ Despite possible discrepancies between the findings at the DNA level, on the one hand, and at the protein level, on the other, p53 immunohistochemistry has value for monitoring the functional status of the protein per se.

An important finding of this study is that high expression of p53 heralds a rapidly fatal clinical course. However, low expression of p53 does not correspondingly predict a favourable outcome. Although an increased percentage of p53-positive cells was found in the majority of the recurrences (Tables IV), no correlation between $\mathrm{p} 53$ expression and tumour grade was revealed. In four studies mainly concerning astrocytomas, the p53 LI reportedly matched histopathological grades. ${ }^{21-24}$ In most, ${ }^{32-35}$ but not all, ${ }^{36}$ studies on glial tumours, mutations in the p53 gene were associated with tumour grade or tumour progress. There is a lack of correlation between p53 LI and tumour grade in oligodendrogliomas, possibly because of defective $\mathrm{p} 53$ genes present in low-grade tumours, while in high-grade oligodendrogliomas both alleles for the gene might have been lost, resulting in negative immunostaining. Alternatively, subsets of oligodendrogliomas with genetic defects without involvement of p53 might exist: in five cases, p53 was not found in the primary tumour nor in the recurrence. Still, high expression of $p 53$ is predictive of short survival, irrespective of tumour grade.

Although in various epithelial neoplasms the p53 LI has been linked with aneuploidy, ${ }^{5,8,19,20}$ no similar relation was shown in the present study. In neoplasms of the lung, the expression of $\mathrm{p} 53$ varied through the cell cycle and increased with the percentage of cells in the S-phase fraction calculated from DNA flow cytograms. ${ }^{11}$ Controversial results concerning p53 expression and proliferation markers in glial tumours exist in the literature, while data specifically addressing oligodendrogliomas are missing. Jaros et al. found a relation between the expression of p53 and the $\mathrm{Ki}-67$ labelling index in adjacent slides of 43 astrocytomas, ${ }^{21}$ roughly indicating a link between proliferation fraction and p53 expression. However, 
no such correlation was found in a study including 46 astrocytomas, in which antibodies against proliferating cell nuclear antigen (PCNA) were used. ${ }^{29}$ The mitotic index did not correlate with the p53 LI in the oligodendrogliomas studied here. Doublelabelling techniques using proliferation markers in combination with p53 antibody might disclose a relation between the expression of mutant p53 and the cell cycle phase at the level of the individual cell.

\section{ACKNOWLEDGEMENTS}

We would like to thank Dr F. J. Bot for his technical advice. Dr Donald E. Born and Ms Amanda W. Jones are acknowledged for critically reading the manuscript.

\section{REFERENCES}

1. Lane DP. p53, guardian of the genome. Nature 1992; 358: $15-16$.

2. Vogelstein B, Kinzler K. p53 function and dysfunction. Cell 1992; 70: $523-526$.

3. Banks L, Matlashewski G, Crawford LV. Isolation of human p53 specific monoclonal antibodies and their use in the study of human p53 expression. Eur J Biochem 1986; 159; 529-534.

4. Barbareschi $M$, Leonardi $E$, Mauri FA, Serio $G$, Paima PD. p53 and c-erb-2 protein expression in breast carcinomas. An immunohistochemical study including correlations with receptor status, proliferation markers, and clinical stage in human breast cancer. Am J Pathol 1992; 98: 408-418.

5. Bosari S, Lee AK, Viale G, Heatley GJ, Coggi G. Abnormal p53 immunoreactivity and prognosis in node-negative breast carcinomas with long-term follow-up. Virchows Arch A [Pathol Anat Histopathol] 1992; 421: 291-295.

6. Campo, E, de la Calle Martin O, Miquel $R$, et al. Loss of heterozygosity of $\mathrm{p} 53$ gene and $\mathrm{p} 53$ protein expression in human colorectal tumors. Cancer Res 1991; 51: 4436-4442.

7. Dolcetti $\mathrm{R}$, Doglioni C, Maestro R, et al. p53 overexpression is an early event in the development of human squamous cell carcinoma of the larynx: genetic and prognostic implications. Int $J$ Cancer 1992; 52: 178-182.

8. Isola J, Visakorpi T, Holli K, Kallioniemi OP. Association of overexpression of tumor suppressor protein $\mathrm{p} 53$ with rapid cell proliferation and poor prognosis in node-negative breast cancer patients. J Nati Cancer Inst 1992; 84: 1109-1114.

9. Iwaya $\mathrm{K}$, Tsuda $\mathbf{H}$, Hiraide $\mathbf{H}$, et al. Nuclear p 53 immunoreaction associated with poor prognosis of breast cancer. Ipn J Cancer Res 1991; 82: 835-840.

10. Kawasaki $\mathrm{Y}$, Monden $\mathrm{T}$., Morimoto $\mathrm{H}$, et al. Immunohistochemical study of p53 expression in microwave-tixed, paraffin-embedded sections of colorectal carcinoma and adenoma. Am J Clin Pathol 1992; 97: 244-249.

11. Morke O, Laerum OD. Flow cytometric measurement of p53 protein expression and DNA content in paraffin-embedded tissue from bronchial carcinomas. Cytometry 1991; 12: 438-444.

12. Ostrowski JL, Sawan A, Henry L, et al. p53 expression in human breast cancer related to survival and prognostic factors: an immunohistochemical study. J Pathol 1991; 164: 75-81.

13. Poller DN, Hutchings CE, Galea $M$, et al. $\mathrm{p} 53$ protein expression in human breast carcinoma: relationship to expression of epidermal growth factor receptor, c-erb-2 protein overexpression, and oestrogen receptor. $\mathrm{Br} J$. Cancer 1992; 66: 583-588.

14. Said JW, Barrera R, Shintaku IP, Nakamura H, Koeffler HP. Immunohistochemical analysis of $\mathrm{p} 53$ expression in malignant lymphomas. Am J Pathol 1992; 141: 1343-1348.
15. Scott N, Sagar P, Stewart J, Blair GE, Dixon MF, Quirke P. p53 in colorectal cancer: clinicopathological correlations and prognostic significance. Br J Cancer 1991; 63: 317-319.

16. Soini Y, Paako P, Nuorva K, Kamel D, Lane DP, Vahakangas K. Comparative analysis of p53 protein immunoreactivity in prostatic, lung and breast carcinomas. Virchows Arch A /Pathol Anat Histopathol] 1992; 421: 223-228.

17. Starzynska T, Bromley M, Ghosh A, Stern PL. Prognostic significance of p 53 overexpression in gastric and colorectal carcinoma. $\mathrm{Br}$ $J$ Cancer 1992; 66: 558-562.

18. Villuendas R, Piris MA, Orradre JL, et al. $\mathrm{p} 53$ protein expression in lymphomas and reactive lymphoid tissue. $J$ Pathol 1992; 166: 235-241.

19. Visakorpi T, Kallioniemi OP, Heikkinen A, Koivula T, Isola J. Small subgroup of aggressive, highly proliferative prostatic carcinomas defined by p53 accumulation. $J$ Natl Cancer Inst 1992; 84: 883-887.

20. Volm M, Efferth T, Mattern J. Oncoprotein (c-myc, c-erbB1, $\mathrm{c}$-erbB 2 , c-fos) and suppressor gene product ( $\mathrm{p} 53$ ) expression in squamous cell carcinomas of the lung. Clinical and biological correlations. Anticancer Res 1992; 12: 11-20.

21. Jaros E, Perry RH, Adam L, et al. Prognostic implications of p53 protein, epidermal growth factor receptor, and $\mathrm{Ki}-67$ labelling in brain tumours. $B r J$ Cancer 1992; 66: 373-385.

22. Bruner JM, Saya H, Moser RP. Immunocytochemical detection of p53 in human gliomas. Mod Pathol 1991; 4: 671-674.

23. Ellison DW, Gatter KC, Steart PV, Lane DP, Weller RO. Expression of the p53 protein in a spectrum of astrocytic tumours. $J$ Pathol 1992; 168: 383-386.

24. Karamitopoulou E, Perentes E, Diamantis I. p53 protein expression in central nervous system tumors: an immunohistochemical study with CMI polyvalent and DO-7 monoclonal antibodies. Acta Neuropathol 1993; 85: 611-616.

25. Ohgaki H, Eibl RH, Wiestler OD, Yasargil MG, Newcomb EW, Kleihues P. p53 mutations in nonastrocytic human brain tumors. Cancer Res 1991; 51: 6202-6205.

26. Kros JM, Van Eden CG, Vissers CJ, Mulder AH, Van der Kwast ThH. Prognostic relevance of DNA flow cytometry in the oligodendroglioma. Cancer 1992; 69: 1791-1798.

27. Smith MT, Ludwig CL, Godfrey AD, Armbrustmacher VW. Grading of oligodendrogliomas. Cancer 1983; 52: 2107-2114.

28. Kros JM, Troost D, Van Eden CG, Van der Werf AJM, Uylings HBM. Oligodendroglioma. A comparison of two grading systems. Cancer 1988; 61: 2251-2259.

29. Barbareschi M, Iuzzolino P, Pennella A, et al. p53 protein expression in central nervous system neoplasms. J Clin Pathol 1992; 45: 583-586.

30. Wynford-Thomas D. Editorial. p53 in tumour pathology: can we trust immunocytochemistry? J Pathol 1992; 166: 329-330.

31. Louis DN, von Deimling A, Chung RY, et al. Comparative study of p53 gene and protein alterations in human astrocytic tumors. $J$ Neuropathol Exp Neurol 1993; 52: 31-38.

32. Chung RY, Whaley J, Kley $\mathrm{N}$, et al. p53 gene mutation and chromosome $17 \mathrm{p}$ deletion in human astrocytomas. Genes Chrom Cancer 1991; 3: 323-331.

33. Fults D, Brockmeyer D, Tullous MW, Pedone CA, Cawthon RM. p53 mutation and loss of heterozygosity on chromosomes 17 and 10 during human astrocytoma progression. Cancer Res 1992; 52: $674-679$.

34. Hayashi $Y$, Yamashita J, Yamaguchi $K$. Timing and role of $p 53$ gene mutation in the recurrence of glioma. Biochem Biophys Res Commun 1991; 180: 1145-1150.

35. Sidransky D, Mikkelsen T, Schwechheimer K, Rosenblum ML, Cavanee W, Vogelstein B. Clonal expansion of p53 mutant cells is associated with brain tumour progression. Nature 1992; 355: $846-847$.

36. Mashiyama S, Murakami Y, Yoshimoto T, Sekiya T, Hayashi K. Detection of p53 gene mutations in human brain tumors by single-strand conformation polymorphism analysis of polymerase chain reaction products. Oncogene 1991; 6: 1313-1318. 